Die Keime der Organismen existiren in der Atmosphäre, und jedes Wasser enthält dieselben nach momentaner Berührung mit der Luft.

Die Entwickelung dieser Keime kann ohne die Gegenwart von Phosphorsäure oder eines phosphorsauren Saizes, oder Phosphor in irgend welcher Verbindung nicht stattinden. In Wasser, wie immer verunreinigt, wenn sonst frei von Phosphors, gedeihen dieselben nicht. Diese unerlässliche Bedingung fuir das Entstehen der niedrigsten Organismen veranlasst Frankland, den bekannten Ausspruch ,ohne Phose phor kein Gedanke" in "ohne Phosphor kein Le. ben" umzuwandeln. (Berichte der deutschen chemischen Ge. sellschaft IV.).

Hlbg.

\title{
Zum Bau und der Natur der Diatomaceen.
}

Auf eine, diesen Titel führende, vor kurzem erschienene Abhandlung des Prof. Adolf Weiss in Lemberg macht Dr. Rabenhorst aufmerksam. Die Resultate dieser „äusserst exacten" Untersuchungen fasst der Letztere in folgenden Punkten zusammen:

1) Die Grundlage des Dia tomeenkörpers ist Pflanzenzellstoff (Cellulose), welche, von Kieselerde durchdrungen, den sogenannten Kieselpanzer darstellt.

2) Die Kieselerde der Diatomeenfrustel polarisirt (entgegen der bisherigen Annahme) das Licht ausnahmslos und meist in ausgezeichneter Weise.

3) Das Eisen kommt als unlösliche Oxydverbindung in der Membran und im Inhalt der Diatomeen vor.

4) Die Diatomeen sind keineswegs, wie bisher allgemein angenommen wird, e in zellige Organismen.

5) Die Frustel ist im Gegentheil zusammengesetzt aus zahllosen minutiösen, aber vollig individualisirten Zellohen.

6) Die Configuration der $\mathrm{W}$ andungen dieser Zellchen, keineswegs aber Areolenbildung, Rippen, Leisten etc. eines einzelligen Pfänzchens ist es, welche die Streifung oder die Striche des sogenannten Kieselpanzers hervorbringt.

7) Die Grösse dieser Zellchen ist sehr verschieden; von $0,008 \mathrm{Mm}$. bis zu $0,00025 \mathrm{Mm}$. 
8) Jedes einzelne dieser Zellchen ist gewölbt und in der Regel in seiner Mittelpartie papillenartig verlängert.

9) Diese Papillen sind es, welche bei schwachen Vergrösserungen als $\mathrm{S}$ triche, bei stärkeren (500-1200 linear) als Perlenschnüre erscheinen.

10) Der verhältnissmässig gigantische Hohlraum zwischen den 2 Frustelschalen (Nebenseiten) ist dem Embryosacko höherer Pflanzen vergleichbar, und es gelang dem Professor $\mathrm{W}$ e is s, in demselben die $\mathrm{Neub}$ ildung neuer Individuen zu beobachten.

11) Die Producte dieser Neubildung weisen auf einen Generationswechsel bei den Diatomeen hin. (SitzungsBerichte d. nat.-wiss. Ges. Isis in Dresden, Mai, Juni, Juli, 1871, S. 98.).

H. $L$.

\section{Senecio vernalis Waldst. et Kit.}

Ueber dieses "neue Unkraut" berichtet E. BeicheEismanns dorf in der Zeitschr. d. landw. Centralvereins d. Prov. Sachsen, (Septbr. 1871, S. 263). Das Frühlingskreuzkraut ward zuerst 1781 vom Prof. Gilibert in Grodno erwähnt; Linné kannte es noch nicht. Es gehört zu den Compositen und erreicht eine Höhe ron 0,3 bis 0,8 M.; der aufrechte, gestreifte, einfache, oben ästige Stengel ist, wie das ganze Gowächs, mit zerstreuten langen Haaren besetzt und trägt denen des gemeinen Kreuzkrautes ähnliche Blätter. Die unteren Blätter sind kurzgestielt, länglich-buchtig, fiederspaltig-doppeltgezähnt, die übrigen umfassend, verschiedentlich fiederspaltig, buchtig - krausgezähnt.

Der Stengel trägt aufrechte, gestielte, in $1-3$ köpfige lockere Gabelzymen (eine Doldentraube nachahmend) gestellte Köpfchen, mit etwa 12 flachabstehenden, strahlenden Zungenblümchen am Rande. Die Hülle ist fast halbkugelig; die Hüllblättchen sind an der Spitze nicht immer !brandig, wohl aber die sehr kleinen ungleichen Deckblättchen. Der haarförmige, sitzende, mehrreihige, hinfällige Pappus der grauweichhaarigen, ungeschnabelten und ungeflügelten Früchtchen ist fast von Scheibenblumenlänge.

Die 2-, selten 1-jährige, von Ende April bis Mitte Juni und später vom Sept. bis zum November blühende Pflanze hat eine jährige Wurzel und gelbe Blüthen, unter denen die Zwitterblüthen einen 2 schenkligen Griffel besitzen. Von dem 